\title{
Electricity, Uncertainty and the Good Life A Comparison of French and Norwegian Household Responses to Policy Appeals for Sustainable Energy
}

\author{
Tanja Winther ${ }^{1} \&$ Sophie Bouly de Lesdain ${ }^{2}$ \\ ${ }^{1}$ Centre for Development and the Environment, University of Oslo, Norway \\ ${ }^{2}$ R\&D, Electricité de France, associated with IIAC-LAU (EHESS-CNRS), France \\ Correspondence: Tanja Winther, Centre for Development and the Environment, University of Oslo, Norway. \\ E-mail: tanja.winther@sum.uio.no
}

\author{
Received: December 19, 2012 Accepted: January 17, 2013 Online Published: January 29, 2013 \\ doi:10.5539/eer.v3n1p71 \\ URL: http://dx.doi.org/10.5539/eer.v3n1p71
}

\begin{abstract}
Targeted by policies on sustainable energy, ordinary men and women are also engaged in the routines and concerns of everyday life. This paper asks to what extent French and Norwegian households link global warming to their own electricity use. Furthermore, we study people's rationales for selecting renewable sources and reducing electricity consumption at home. Empirical material was collected in France and Norway. We draw on a practice theory framework. The purpose of the paper is to use a comparative analysis for highlighting important aspects of the electricity cultures in each country, thereby accounting for why the French and the Norwegians respond to appeals for sustainable energy in the ways they do.

The results show that people in both countries tend to regard their own electricity use as disconnected from global warming. This is partly due to the high share of non-fossil power production in both countries, but we also suggest that certain denial mechanisms reinforce the idea that electricity consumption is disconnected from environmental challenges. The French respondents relate to the state-owned supplier EDF. They are preoccupied with physical and financial risks and regard electricity as a necessity. Conversely, the Norwegians value electricity in itself as a non-problematic good to which they think they have a claim as Norwegian citizens. Although the cost of electricity has an equal share of the household budget in both countries, the French practice a savings culture to a much greater extent than Norwegians do.
\end{abstract}

Keywords: Perceptions of electricity, comparison France and Norway, electricity cultures, sustainability

\section{Introduction}

Stephanie, a mother of two living in Paris, always makes sure to turn off the electric radiator before leaving her flat. She says she wants to reduce the physical danger. Per, a Norwegian who lives with his family in a detached house in the northern part of Norway, says he enjoys having a quick shower in the morning. After showering and shaving, he is done.

Informed by the threat of global warming, current policies are aimed at reducing energy consumption and increasing the share of renewable sources (Note 1). Ordinary men and women are being targeted by such policies on sustainable energy. At the same time they are engaged in the routines and concerns of everyday life. In this comparative paper we ask to what extent French and Norwegian households link global warming to their own electricity use. Furthermore, we study people's degree of interest in renewable electricity as well as their motives for reducing electricity consumption at home.

Our work follows practice theory (Bourdieu, 1977; Sewell, 1992; Warde, 2005; Ortner, 2006) and associated socio-technical approaches for understanding people's energy use (Wilhite, Shove, Lutzenhiser, \& Kempton, 2000; Shove, 2004; Henning, 2005; Aune, 2007; Winther, 2008). Changes in consumption patterns require both structural changes and end-users' cooperation, and the field of energy appears particularly resistant to change due to the often habitual, non-reflexive character of such practices (Røpke, 2009; Wilhite, 2008; Maréchal, 2009). When asked in polls, the majority of people in France and Norway express concern about climate change (Ademe, 2012; Commissariat Général au Développement Durable, 2011; CICERO/Synovate, 2010). Europeans 
are also generally positive towards renewable energy sources (Markard \& Holt, 2003; Boardman \& Palmer, 2007; Hansla et al., 2008; Litvine \& Wüstenhagen, 2011). However, related to the influence of structural factors, people's daily energy practices are often motivated by other concerns which may contradict their "green" dispositions (Røpke, 2009; see also Sælen et al., 2012).

In the present study we seek to understand Stephanie's, Per's and other people's rationales for doing what they do with electricity. The purpose is to use a cross-cultural examination of France and Norway in order to highlight some of the important technical and social aspects that make up the "electricity culture" in each country. Such insight, we argue, is important for understanding how people respond to policy appeals for sustainable energy. In our treatment of electricity, information and uncertainty we will also draw on a cultural concept of risk (Douglas \& Wildavsky, 1983; Douglas, 1990; Peretti-Watel, 2010) and the "social organisation of denial" (Zerubavel, 2006).

Within the context of European electricity markets, information measures are considered as an important tool for ensuring sustainable consumption. The electricity bill is the most important means of communication from supplier to customer. The bill conveys information about the level of consumption in a given period of time as well as the amount due to be paid. Within the market logic embedded in the deregulated European electricity sector, customers are expected to reduce consumption or select another supplier when the cost/price becomes high. Furthermore, current EU regulations require that the bill provides information about the electricity's origin (Note 2). The assumption is that environmentally conscious consumers who receive such disclosure information will select renewable products or suppliers that offer electricity with a renewable guarantee (Boardman \& Palmer, 2007; Aasen et al., 2012; Winther \& Ericson, 2012). Finally, information campaigns are considered as an important means for obtaining energy efficiency (Note 3). What the last two measures have in common is that information is used as a strategy for encouraging individuals to adopt pro-environmental behaviour. According to practice theorist Elisabeth Shove (2010), the underlying thesis informing such policies is rooted in behaviouralism and the view that individual action is both the cause of environmental damage and the key to its solution. Our work includes an examination of people's perceptions of billing information and discusses to what extent such information is relevant for and/or affects electricity use in everyday life.

The outline of the paper is as follows: Section 2 accounts for the methods used for collecting the empirical data in France and Norway. In Section 3 we present the two electricity systems and discuss some of their central characteristics. Section 4 treats people's degree of concern for environmental challenges such as global warming and discusses to what extent they perceive electricity as connected to such challenges. Section 5 focuses on people's perceptions of their suppliers, bills and billing information. Section 6 accounts for people's motives for saving electricity at home. Section 7 provides a summary of contrasts and similarities in French and Norwegian perceptions of electricity. Section 8 concludes.

\section{Method}

We base the study (Note 4) on in-depth, semi-structured interviews with people in their homes as well as on focus group discussions. The French and Norwegian co-designed interview guides included topics such as people's perceptions of the environment and climate change; their perceptions of electricity and its origin; their thoughts about the possibility of changing supplier; their electricity use at home; how and to what extent they try to reduce consumption; how they manage their electricity bills and other issues. In the Paris region, 20 interviews were conducted in 2011 (Note 5), just before the Fukoshima nuclear accident in Japan. In Norway, 11 interviews were conducted by the Norwegian researchers in 2009 in Kirkenes and Vadsø, two towns in the very northern part of the country. In addition, four focus group discussions involving 32 participants in total were organised in Kirkenes in December 2009.

The sampling method involved selecting individuals from the middle class to obtain a certain degree of diversity of users within this segment in each country. In France, the interviewees, all of whom were EDF customers, were selected to ensure a wide range of ages and generational belonging, the presence or not of children in the household, and diversity in terms of people's marital status, education level, technical type of heating and whether they were homeowners or tenants. In Norway, all the people interviewed owned their own houses and most of them were married with children living at home. Due to the challenge of recruiting people at all, the Norwegian interview sample is likely to contain more individuals who are more interested in energy than is the case among Norwegians in general (Note 6). We balance this by drawing on the material from the focus groups, to which participants were recruited randomly, while ensuring diversity in terms of gender and generation. 


\section{Two Atypical Electricity Systems}

The French and Norwegian electricity systems are unique in a European context, primarily in that power production is mainly based on non-fossil fuels. This implies that production represents a limited amount of greenhouse gas emissions. In France, 74 percent of the production is based on nuclear power (Note 7), whereas in Norway renewable hydropower constitutes as much as 96 percent of the country's electricity production. Both countries exchange power with surrounding countries. Such exchange is particularly important for Norway (Note 8 ) given that hydropower production depends on variations in rainfall.

Related to their distinct types of production, the two electricity systems have evolved and are organised in radically different ways. The establishment of nuclear power plants in France came in response to the severe energy crisis in the 1970s. The selection of nuclear power required that the state through Electricite de France (EDF) maintained responsibility for production and supply. French households were included in the electricity market in 2007 (Note 9). Currently, eight percent of French customers have chosen a supplier other than EDF (Commission de Régulation de l'Energie, 2011) and some among the alternative suppliers provide 100 percent renewable electricity. A testimony to the continued state control in France is the fact that the government sets EDF's prices after having consulted the regulating authorities. EDF customers may choose between various tariffs, including one that offers different prices during daytime and night-time. There are also social tariffs in France offered to less privileged groups. 21.5 percent of French families say they limit energy consumption for heating purposes because it is too costly, and 15 percent say that they suffer from a low indoor temperature (Devalière, Briant, \& Arnault, 2011) (Note 10).

In Norway, the rivers and waterfalls that were tapped as an energy source beginning in the early 20th century are located throughout the country. Thus Norway had, and still has, a range of local producers and suppliers (Note 11), commonly owned by either municipalities, the state or private actors. Together with the political emphasis on economic efficiency at that time, this decentralised structure encouraged the liberalisation of the Norwegian electricity market in 1991, which included households from the start. Today, about one-quarter of Norwegian households have a supplier other than the main one in their area, and the domestic electricity market is considered mature. Prices are highly volatile in Norway and may vary significantly on a daily, monthly or yearly basis, depending on a customer's type of contract. Such variation is market based, and the prices are not set according to the time of day. There are no social tariffs for electricity in Norway. Table 1 summarises some of the important characteristics of the French and Norwegian electricity systems.

Table 1. Characteristics of the French and Norwegian electricity systems (copyright: authors)

\begin{tabular}{lll}
\hline & French electricity system & Norwegian electricity system \\
\hline Effect of energy crisis in the 1970s & Severely affected & Not affected \\
Production (dominant) & Nuclear & Hydropower \\
Sector structure & Deregulated Centralised, & Deregulated \\
Electricity price & government control & Decentralised, many actors, competition \\
Differentiated prices day/night & Low, stable & Low on average, but highly volatile \\
Social tariffs & Yes (voluntary) & No \\
Electricity consumption per capita & Yes & No \\
\hline
\end{tabular}

The two countries have in common that electricity is relatively cheap (Note 12), although consumption levels vary. Per capita, Norwegians consume more than 2.5 times the electricity that the French do (Note 13). It should be noted that fuels other than electricity, such as gas and oil, are also common for cooking and heating in France. Many Norwegians use firewood for heating as a supplement to electricity. In both countries, notably, we find that households spend about four percent of their budget on energy (Commissariat Général au Développement Durable, 2010; our estimations for Norway (Note 14)). Although there is substantial variation in people's ability to pay, the four percent share is relatively low in the European context. We may therefore assume that our middle-class French and Norwegian respondents can afford to pay for electricity. We will now turn to the customers and examine how they perceive the challenge of climate change and a range of issues related to electricity. 


\section{Concern for Climate Change and the Environment}

The majority of the Norwegian respondents related to climate change in an abstract and distant, if also sometimes emotional, way. For example, Linda, a young woman, said she fears how the world will be when her children grow up. Sverre, a 47-year-old man, associated the issue of "environment" (Norwegian: miljø) with natural resources. He declared that he believes that "the environmental problem is the most serious threat that the world is facing today". He elaborated by saying that "if everyone is allowed to increase their consumption by two percent, this will not be possible because the resources of earth are limited". When asked specifically about his view on climate change, he said that he is not very concerned about the problem and that he does not know if such changes are caused by human activity or not. More women than men said they were worried, and by and large, our Norwegian respondents seemed modestly concerned about climate change.

In Paris people expressed more concern. When talking about the effects of global warming some would also bring in their personal experiences:

There are more and more natural disasters, so either they're getting more and more media coverage or something really is out of whack, with increasingly strong hurricanes or that sort of thing. And what's really alarming or weird is that, I don't know, I've been in Paris for 10 years, it's bizarre that winters are increasingly harsh and, consequently, that raises an energy issue because being really well insulated when you are sweating through heat waves in the summer and you've got colder and colder winters, you find yourself with the kind of climate they've got in Canada, and so there's more $\mathrm{CO}_{2}$, which is making the North Pole melt (Baptiste, 30 years, Paris).

However, some French interviewees also expressed scepticism about the reality of the problem: "We don't know what happened 2,000 or 500 years ago. No one was around to study and see it." (Jacques, 62 years, Paris). In general, though, most respondents in both countries tended to acknowledge the occurrence of human-made global warming. The two groups also generally agreed that it is primarily the responsibility of politicians, rather than individual consumers, to act and provide solutions to the environmental challenges. Some Norwegians regarded the lack of strict environmental policies as a sign that the government itself has doubts about the problem. French respondents tended to stress that the industry and EDF also have a responsibility to provide solutions.

It is important to note that neither the French respondents nor the Norwegians saw a connection between the problem of climate change and individual electricity use. Given the two countries' large share of non-fossil production and people's awareness of this fact, the reason for this disconnection seems obvious at first glance. However, in Norway, the power exchange with other countries implies that the sources of the electricity available consist of a mix of fuel types, ranging from hydroelectric and nuclear power to coal, natural gas and wind-based sources. Although the annual, net share of imported or exported electricity tends to remain in the single digits, the exchange takes place on a daily basis and amounts to considerable quantities of exchanged power. Participants were well aware of this exchange. They spoke about the imported power as being "polluted" (forurenset) and contrasted this with the "clean" (ren) and "green" (grønn) Norwegian electricity. Many also expressed a strong sense of collective ownership of this resource ("our rivers"), which they seem to value as a good in itself (see Westskog \& Winther, in progress). However, very few pointed to the environmental aspects of increased imports and nobody referred to polluting imports as a rationale for saving electricity at home. It therefore seems that our respondents also wanted to think of Norwegian electricity as being clean, conceptually reproducing the national boundary.

Norwegians' strong conviction that they only consume renewable electricity has turned out to be a barrier to their acceptance of the electricity labelling scheme, in which Guarantees of Origin are traded across national borders. Norwegian producers have responded as anticipated by having Guarantees of Origin issued on the basis on their renewable production. However, most of these guarantees are exported to the European continent. Norwegian households are not willing to pay extra for electricity with a renewable guarantee (Westskog, Winther \& Strumse, 2011; Winther \& Ericson, 2012). A typical response to such an offer was: "This is ridiculous in Norway. The electricity we get is already green." The resulting paradox is that Norwegians continue to think that they consume renewable electricity, as do customers in Belgium and Germany who have purchased electricity with guarantees issued in Norway.

In contrast to the green and clean electricity perceived by Norwegians, our French respondents were quick to highlight electricity's association with nuclear risk. Such risks were said to be high at the production and waste stages, and low at the consumption stage. People's attitudes towards nuclear production and waste, not in terms of the energy source per se but rather its exploitation by EDF, ranged from full-fledged opposition to acceptance 
and confidence. Between these two positions, some expressed willingness to compromise. Those with a favourable attitude and those willing to compromise tended to put off questions about risk and waste management. Within this discourse, safety is said to be taken care of in France, and nuclear risk is perceived to be situated far away in other countries associated with less management expertise or even poor management. Today, EDF manages the issue of waste, the refrain goes. Tomorrow is another day, and doing without nuclear energy is not possible: "I don't think we have an alternative to nuclear energy today" (Baptiste, 30 years, Paris). In this case, people's attitude towards risk reflects their attitude towards time, allowing those who favour nuclear energy or who prefer compromise to mentally postpone the waste issue. In contrast, the "anti-nuclear" segment actively focused on future risks: “... the problem is simply being postponed” (Sophie, 37 years, Paris).

In their treatment of European opinions regarding radioactive waste, Boardman and Palmer (2007) observed that it "appears to be a greater concern (...) where there are no nuclear power stations, compared to countries with an active nuclear power program". They concluded that nuclear risk is minimised by those who depend on this kind of source. However, there is another possible interpretation of these stances regarding nuclear energy, which tallies with our interviews: being in favour of nuclear energy, or at least not being against it, does not mean that the risks are ignored, but that they are evaluated in light of the alleged economic risks of phasing out nuclear energy. In a recent study Brouard et al. (2012) found that "only eight percent of people in favour of nuclear energy consider it safe, and a tiny minority believe that nuclear waste does not pose problems". Thus it seems that the current economic crisis has relegated the risk issue related to nuclear energy to a position of secondary importance, supplanted by the issue of unemployment. In a semiotic analysis, Fodor (2012) argues along such lines, observing that the economic crisis replaced environmental issues in the media a few months after the nuclear accident in Fukushima in March 2011 (Note 15). This observation shows that risks and risk management are hierarchically ordered. The concept of risk often also has a flavour of being scientifically objective, which may camouflage its cultural and context-dependent aspects. Peretti-Watel (2010) speaks of a cultural bias in this regard:

... on the one hand, our culture gives us a specific perception framework, which determines how we grasp the world around us, how we interpret the information that reaches us, and therefore also how we evaluate risk. On the other hand, our values give the risks around us meaning, filling them with special significance...

The French cultural concern for nuclear risk does not have a parallel in our accounts from Norway. This is not surprising, given that Norway does not have nuclear power plants, though the country did experience some of the effects of the Chernobyl disaster in 1986. In both countries, however, there is a tendency to play down certain facts that in reality implicate consumers in the problem. Most notably, people tend to disregard the links between production and consumption. When the French respondents identified the environmental challenges related to electricity, they primarily did so by limiting the issue to the industry, production and/or the future, disconnected from their own consumption and daily life. In a similar vein, Norwegians tended to disregard the links between imported polluting electricity and their own consumption and insisted that Norwegian electricity is renewable. One may regard such dynamics as reflecting processes of "denial" (Zerubavel, 2006), a concept with close associations to Douglas' cultural model on risk. New information which does not fit with existing ideas is systematically disregarded or collectively denied while culturally anchored ideas remain strong: "nuclear is risky on the production side" (France) and "electricity is renewable per se" (Norway). Compared to, say, tomatoes or coffee, electricity has a particularly complex nature from production to consumption, including its invisibility, instant consumption and integration into multiple systems and markets that stretch beyond national boundaries. We suggest that these multifaceted aspects serve to strengthen processes of denial, thereby reducing the likelihood that customers will absorb new information about electricity and act in response to this.

\section{Customers' Perceptions of Suppliers, Bills and Billing Information}

Electricity customers' willingness to switch supplier is a central premise for the market to work as intended and for facilitating a shift towards renewable electricity production. In Paris, all the families were EDF customers, which may have made them stress their preferences for the company rather than its competitors. However, EDF has 94 percent of the French household market; thus customer loyalty is generally high. Below we refer to people's accounts in order to understand why the French interviewees hesitate to change supplier and how they perceive the electricity bill. This will be contrasted with the Norwegian material.

When the French were asked if they had ever considered changing supplier, many aspects perceived as barriers came up. 
...why have I not changed, then? Mostly for reasons of continuity of service. I am concerned that the new suppliers will not be able to maintain service, and if they turn out to be a failure, then what? (Céline, 25 years, Paris)

With respect to changing the contract, I have the impression that it would take time to make comparisons, and I'm afraid it would also cost money (...). As a result, between one and the other, I don't know if I would save very much. And to my mind, I imagine that the competitors use the same electricity as EDF. Does this mean that they purchase electricity from EDF which they would then turn around and charge back to me? In the end, do I really gain anything? I don't know at all. (Solange, 53 years, Paris)

As these quotes reflect, the French arguments for not wanting to change supplier centred on the increased risk of additional costs (money, time, stress) for obtaining what some think would be a highly unreliable energy service. Many also thought that the electricity they would buy from other suppliers would be produced by their current supplier, EDF. Quite a few expressed positive attitudes towards renewable sources, but the perception that "it will always come from EDF" negatively affected their interest in changing to suppliers who offer 100 percent renewable (Note 16). Other studies confirm this observation that not all French are fully aware of how the electricity market works (Note 17). Moreover, our respondents associated the promotion of renewable electricity in France with the world of business, often evaluated in negative terms ("tax exemptions", "unscrupulous installers"). Finally, renewable electricity is more expensive than conventional power from EDF, and this fact probably contributes to French customers' scepticism towards changing supplier.

In striking contrast to the French families' reluctance to leave EDF, Norwegian customers are accustomed to changing supplier. Households are allowed to do this every second week without a fee. Our sample in Northern Norway is untypical in the sense that only six percent of the customers, similar to the French share, had a supplier other than the main one in the area (the national average is 26 percent, as noted). But whereas the French barriers to changing supplier were related to a feeling of risk, people's lack of insight into the market, and EDF's low price, the Norwegian customers under study seemed to have taken a pro-active stance to support their local, municipality-owned supplier. Admittedly, a few showed a concern for what would happen if they changed supplier and it went bankrupt, but they were highly aware of their role as customers in a market. Many said that their reason for not changing supplier is that the prices do not vary significantly. In light of our previous discussion of the labelling scheme for electricity, it is worth noting here that Norwegians have fully accepted the arrangement that electricity can be bought from various suppliers in an open market, and thus also the financial system underlying this market which traces the amounts of electricity supplied and consumed. As seen, however, they do not correspondingly acknowledge the tracing system behind the labelling regime, but instead hold on to the idea that all electricity consumed in Norway is renewable.

People we interviewed in France did not seem interested in changing supplier. Conversely, the Norwegians feel free to leave their local supplier without taking on additional risk. These two distinct customer-supplier relationships are potentially relevant for how people perceive the bills. Both the French and the Norwegians said they normally ignore the billing information except for looking at the amount due and the corresponding date. When asked specifically to comment on the content of the bills, people in both countries said they look for variation compared to previous bills. However, the status of the bill differed in the two contexts. Norwegians said they simply register the amount to be paid to their local supplier without expressing a concern for a lack of choice or mentioning the relatively high share of taxes applied to electricity in Norway. In contrast, the French interviewed associated the bill with a form of tax (Note 18). First of all, the bill was said to be an unavoidable, fixed expense in line with municipality taxes, mortgage payments, and costs for insurance, water and gas. Norwegians did not make similar analogies. Secondly, as in Norway, a substantial part of the French bill is dependent on various governmental taxes, but in Paris this issue notably became a topic during the interviews, which seemed to strengthen the association between bills and taxes. Thirdly, some of our respondents pointed to the fact that bills in France can be used as legal proof of residence; thus bills are documents of authority. In France, there is an important association between electricity bills and the government, whereas Norwegians are more likely to view the bill as reflecting a symmetric relationship between supplier and consumer in an open market.

Interestingly, despite these differences in customer-supplier relationships and the status of the bill, people in both contexts were reluctant to act on the message in additional billing information such as advice on how to save electricity or chose renewable products (Norway). In general, the issue of trust is important when information is assessed, and in both countries trust centred around two main discourses. Firstly, there was a techno-economical discourse, that is, people's perceptions of the supplier's degree of accountability and 
accuracy in measuring and charging consumption, ensuring security of supply, etc. Here we find that people's level of trust is high in both countries, except for EDF customers' relatively low trust in suppliers other than EDF. Secondly, there is a commercial discourse in which customers evaluate the advice (information) coming from the supplier in relation to their perceptions of the supplier's underlying motives. For both France and Norway we find that customers expect that their supplier is commercially oriented. They therefore question advice about sustainable consumption. As a consequence, the information is disregarded. This indicates that billing information has limited potential for modifying people's practices in a sustainable direction.

One of the central conditions for current EU policies to work as intended is that electricity customers, out of a concern for the environment, are willing to change supplier and that they otherwise act based on information provided on the bills. We have established that both the French and Norwegians, although they have quite different electricity systems, have few incentives for selecting suppliers who offer renewable electricity. Norwegians are generally open towards changing supplier, but not for environmental reasons. In France we found that some people might be motivated to shift supplier out of environmental concern had it not been for the perceived risks involved in leaving EDF, the higher cost of renewable electricity and the general lack of clarity as to how the electricity market works in France. We also know that customers in general tend to disregard billing information and that they lack trust in messages on sustainability coming from suppliers whom they perceive to be commercially motivated. We will now discuss the other important aspect of sustainable electricity in relation to practice, that is, people's motives for saving electricity at home.

\section{Electricity Use and Motives for Saving}

The French respondents' focus on risk and uncertainty connected to production and the prospect of changing supplier corresponds to how they perceive electricity's uses in everyday life. First of all, several interviewees highlighted the physical danger involved when appliances are used. This makes some of our French respondents adopt a restrictive user-practice: "Anything that can be unplugged is unplugged. I don't like leaving them plugged in as I'm always afraid that there could be a short circuit" (Jacques, 41 years, Paris). In comparison, none of our Norwegian respondents brought up the issue of physical danger connected to electricity use (Note 19). This is a striking finding compared to the highly articulated French concern about avoiding the physical danger of electricity by turning off appliances and thus reducing consumption.

A second reason for saving electricity in France is economically motivated. As noted, the cost of energy in France is among the lowest in Europe. Nonetheless, some of our French respondents said they experience the cost of electricity as a financial burden, and 46 percent of the French have reported that they think their bill is too high (Ademe, 2012). Strategies to reduce the bill include paying on a monthly basis in order to spread the expenses or trying to adjust consumption to the hours of the day when the tariff is lower, such as by washing clothes late in the evening. Most of the French respondents seemed to have a genuine economic motive for trying to reduce consumption, but many felt that they had already reduced consumption to a minimum. They regarded their low bill as proof of their low level of consumption. A similar financial concern was not observed among Norwegians. Here, cost-saving aspects were sometimes mentioned as a rationale for investing in energy saving technology such as heat pumps. But those who had invested in such devices described this more as a smart or clever decision, "why spend more than necessary?", than as an urgent need to save on costs. To the French who regarded their low bill as proof of their low level of consumption, cutting down seemed to require a "mental" effort in return for a limited financial gain: "I'm not going to bother making an effort for just 30 Euros" (Baptiste, 30 years, Paris).

A third aspect connected to savings relates to social norms for electricity use and savings. The French reported that they do many small things on a daily basis to save electricity. Many said they would switch off the lights when leaving a room, turn down the thermostat when they are away, etc. Such acts of curtailment in French homes seemed to be "automatic" gestures, often motivated by a desire to be thrifty. Many expressed a concern for not being wasteful and this stance appears as a cultural value, as a desirable way of living: "I only consume what I need, no non-essentials. That doesn't interest me." (Céline, 35 years, Paris).

The anti-waste attitude probably has its roots in the French energy crisis of the 1970s when extensive television campaigns forwarded the slogan "In France we don't have oil but we have ideas". Measures aimed at careful energy management emerged at that time and still prevail today. For instance, summer time and winter time were introduced (in Europe at large) to ease the impacts of the energy crisis. This situation influenced several generations in the 1970s and was followed by a repudiation of excessive energy consumption by succeeding generations (Note 20). Consequently, today's younger generation also seems motivated by an anti-waste discourse. "Being careful about electricity" was mentioned in line with a whole range of daily gestures, from 
water use to transport and waste sorting. Together with these related practices, electricity use forms part of a whole, a category for anti-waste behaviour as such. This was also seen when people said they can make up for one particular extravagance by making savings in other areas, which also expresses a feeling of guilt. For example, some said they may have a nice hot bath and make up for it by turning off the tap while brushing their teeth.

On a daily basis, the moral and guilt-inducing dimension of consumption seeps through French media reports on the environment. A lexicon of dependence and addiction is employed in the press, for example by using expressions such as "energy sobriety" (Fodor, 2012). In France, waste is not just an environmental and economic issue, but a moral one as well.

In the case of Norway, people's perceptions of electricity as green and clean produce a very low level of environmental motivation for reducing electricity consumption at home. Also, they did not associate electricity with financial worries. Moreover, our respondents and focus group participants seemed far from adopting a savings culture similar to the one observed in France. On the contrary, to the majority of Norwegians we met, electricity use falls into a category different than other practices associated with environmental behaviour such as waste management and transport. The range and magnitude of steps to save energy reported by Norwegian respondents were far less than what was found in France. Illustrative of this difference is also our observation that the French have greater awareness about the system for labelling appliances than Norwegians (Note 21).

When Norwegians explained their high level of consumption, many mentioned the cold climate (Note 22) as a reason why things are difficult to change, concluding "there is little we can do". A couple of elderly women in a focus group agreed that they have tried to keep consumption at a minimum all their lives and now feel that they have the right to keep it a bit warmer inside. Some participants would blame young people for taking too long showers and changing their clothes every day, while others pointed to the youth as being a particularly conscious group due to the environmental education they have received in school. Initiatives such as using energy-efficient lights and showers were sometimes mentioned, but far from appreciated by all. For example, Birger said that his family used to keep a low-consuming shower, but he does not want to use it anymore: "That is a luxury I allow myself". In line with what many French and Norwegians told us, he explicitly referred to the desire for comfort (Note 23) as a barrier to saving electricity at home. But the Norwegians we met seemed more concerned about "not being fooled" (ikke bli lurt), for example when responding to information, than modifying their practices in a sustainable direction. Both the French and the Norwegians expressed a desire for comfort, but in France, the articulated concern for comfort was more balanced with the value of not wasting.

\section{A Summary of Contrasts and Similarities in French and Norwegian Perceptions of Electricity}

We have examined the ways people talk about electricity, electricity use and the degree to which they try to save electricity at home. The comparative material from France and Norway helped to clarify some of the central aspects of the electricity culture in each country. In France, multiple dimensions of risk are a crucial factor in how people relate to electricity as a technology, to their supplier and bills, and to electricity's services and uses in everyday life. Electricity is perceived as a necessity for living. The French interviewed also expressed a desire to not waste resources; thus we denoted "anti-waste" as a French cultural value and showed that electricity consumption forms part of this category. In comparison, electricity in Norway is valued both as a concept and as a physical good. The idea of having easy access to the clean and safe electricity stemming from "our rivers", as our respondents emphasised, forms part of the good life. So does electricity's various uses. Our material confirms what Wilhite et al. (1996) observed in the 1990s: Norwegians highlight the value of "keeping it warm and cozy" indoors. Norwegians are significantly less preoccupied with trying to reduce electricity consumption compared to the French respondents. Table 2 summarises the findings on French and Norwegian perceptions of electricity and related issues. 
Table 2. Perceptions of electricity and related issues among French and Norwegian respondents (copyright: authors)

\begin{tabular}{|c|c|c|}
\hline & France & Norway \\
\hline Concern for climate change & $\begin{array}{l}\text { Considerable, but not relevant } \\
\text { for household consumption of } \\
\text { electricity }\end{array}$ & $\begin{array}{l}\text { Modest, but not relevant for } \\
\text { electricity }\end{array}$ \\
\hline Responsibility for sustainable energy & Politicians, EDF, industry & Politicians \\
\hline Overall conceptualisation of electricity & $\begin{array}{l}\text { Risky production and waste } \\
\text { (nuclear) }\end{array}$ & $\begin{array}{l}\text { Clean, safe and "ours" } \\
\text { (hydropower) }\end{array}$ \\
\hline Information about electricity's origin & Trusted, but mostly ignored & $\begin{array}{l}\text { Campaign not understood, not } \\
\text { trusted, ignored }\end{array}$ \\
\hline Relationship with supplier & $\begin{array}{l}\mathrm{EDF}=\text { government, } \\
\text { risky to change supplier }\end{array}$ & $\begin{array}{l}\text { Accustomed to changing supplier } \\
\text { who is profit seeking }\end{array}$ \\
\hline Status of electricity bill & “Tax", proof of residence & Insignificant \\
\hline Electricity use & May be dangerous, costly & Safe, cheap \\
\hline Motives for saving electricity & $\begin{array}{l}\text { Saving culture/moral } \\
\text { dimension } \\
\text { Concern for costs } \\
\text { (Environmental rationale) }\end{array}$ & $\begin{array}{l}\text { Laissez-faire. Some invest in } \\
\text { energy saving equipment. Fear of } \\
\text { being fooled. }\end{array}$ \\
\hline Perception of electricity in everyday life & $\begin{array}{l}\text { A necessity for living the good } \\
\text { life }\end{array}$ & $\begin{array}{l}\text { A central part of living the good } \\
\text { life }\end{array}$ \\
\hline
\end{tabular}

Generally, we follow the literature that highlights the strong, habitual character of people's energy practices at home, and this has relevance for people's responses (or lack of such) to policy appeals for sustainable energy. In addition, the Norwegian perception of electricity as a culturally attractive object and people's explicit focus on comfort and lack of financial or other worries indicate that Norwegian electricity consumption is hard to change through information campaigns. In comparison, many of our French respondents appeared to perceive that they have already done what they can to reduce electricity consumption. They seem nonetheless to be more open to ideas that could help them reduce consumption, especially if the cost and the physical danger were reduced at the same time.

\section{Conclusion and Outlook: Whose Responsibility to Provide Change?}

This study has shown some important similarities and differences with regard to how the French and Norwegian people under study relate to electricity and sustainable consumption. In this conclusion we discuss our findings in relation to some central concepts in the literature. We seek to highlight some of the difficulties associated with introducing general energy policies in highly distinct contexts. We argue that this endeavour is particularly challenging when the effect of a given policy tool depends on the conscious actions of individual consumers. We end by touching on the issue of responsibility in relation to sustainability and by indicating in what directions French and Norwegian electricity policies are moving at present.

Shove (2010) documents that the concept of individual choice is central within behaviouralist theories and policies. In the case of electricity labelling, the underlying presumption is that environmentally conscious consumers will "be able to choose a supplier on factors other than price, making an informed decision which reflects their environmental values" (Boardman \& Palmer 2007). In combination and over time, an open electricity market, disclosure information and environmentally conscious consumers are expected to produce a shift towards less polluting electricity sources. Our empirical results demonstrate that these presumptions are far from realities in France and Norway. First of all, the countries have in common that their power production is primarily based on non-fossil sources, and the fact that production does not leave substantial footprints of $\mathrm{CO}_{2}$ was reflected when people expressed that they regard electricity consumption as disconnected from the challenge of global warming. However, by drawing on Zerubavel (2006) we found certain processes of denial at play in each country related to people's perceptions of the links, or rather, disconnections between production and consumption, which served to strengthen the conceptual distance between global challenges and people's daily life. One effect of this is that electricity consumers in France and Norway do not feel, or do not want to feel, responsible for solving 
grand environmental challenges. Another effect of the disconnection is that disclosure information about electricity's origin is perceived as irrelevant by most consumers.

Secondly, the presumption that customers are generally prepared to swap supplier is problematic. The few among the French who might have been interested in pursuing renewable electricity and select suppliers who offer such electricity felt restricted by a range of factors (higher cost, risk of switching supplier). Norwegians are accustomed to changing suppliers, but as noted, they will not do so to obtain electricity with a renewable guarantee. Thirdly, to the extent that French and Norwegian consumers read the information at all, they were sceptical towards receiving advice on sustainable behaviour from perceived profit-maximising suppliers. In sum, the labelling regime introduced throughout Europe is oriented at individual, environmentally conscious customers. Because the premises on which the regime is based do not match realities in our two countries, it has not produced substantially more demand for renewable electricity.

In contrast to behaviouralist approaches focusing on attitudes, behaviour and choice (Note 24), we have tried to base the discussion on an integrated analysis of the socio-technical electricity systems on the one hand (Table 1) and people's perceptions, explanations and habits on the other (Table 2). By employing comparison as a tool we sought to clarify how the various traits in each country make up a specific electricity culture. We argue that insight into such cultures provides a first step to understanding how sustainable consumption could be reached. It is worth listening to our French and Norwegian respondents when they hold policymakers (in France: also EDF and the industry) responsible for providing sustainable solutions. They can be seen as opposing the behaviouralist presumption that environmental damage is a consequence of individual action involving individual responsibility, which Shove (2010) rightly points out is a highly political stance. Our respondents seem to want an alternative policy which does not ask them as individuals to respond to selected pieces of information. As one of our female participants in Norway put it when asked what could make people save energy:

I think that politicians should set the standard and make some legally binding agreements, and we will also take personal responsibility. But if they do not take responsibility, it is not likely to be of any use. (Focus group participant, Norway)

At present France and Norway seem to be moving in different directions in terms of how to handle future electricity consumption, France by tightening consumption and Norway by expanding production and consumption. The French government has recently proposed a new law introducing progressive tariffs (Assemblée Nationale, 2012). The law aims to place a higher tax per kilowatt hour on consumption over a given level so that those who consume more will pay more than what is the case today. The wording in the proposition includes rather strong judgments, such as "extravagant" and "virtuous" consumers. This might resonate with the anti-waste stance among many of our French respondents but not necessarily with the position of those who think that consumption is unproblematic as long as one pays for it. Norway, by contrast, has recently been included in a market for Tradable Green Certificates (TGCs) with Sweden. As a result, the government has committed itself to substantially expanding the capacity of Norwegian renewable production. Consumption is likely to increase.

Debates are bound to appear in both countries. What limit should define the boundary between normal and excessive consumption in France? What rivers and land should be exploited in Norway for ensuring new renewable production plants? Each of the new policies seems to reinforce important characteristics of the French and Norwegian electricity cultures and may therefore actually succeed by being accepted. For a variety of reasons, many French, like Stephanie whom we introduced in the beginning of this paper, will try to use as little power from EDF as they can. Per and other Norwegians will use even more electricity than before. Forthcoming information campaigns are not likely to change such predicted patterns.

\section{Acknowledgements}

We thank our project colleagues at CICERO, Lillehammer University College and EDF, in particular Hege Westskog and Sylvie Douzou, for their kind support. We also thank participants in the panel W050 "Uncertain futures: the cultural dynamics of energy transition" during the EASA Conference in Nanterre, France, 2012, for providing valuable comments. Connie Stultz proofed the English language. 


\section{References}

Aasen, M., Westskog, H., Wilhite, H., \& Lindberg, M. (2010). The EU electricity disclosure from the business $\begin{array}{lllll}\text { perspective-A study from Norway. Energy Policy, 38(12), 7921-7928. } & \end{array}$ http://dx.doi.org/10.1016/j.enpol.2010.09.013

Ademe. (2012). Environnement, énergie: quelles évolutions des opinions et pratiques des Français. Ademe \& vous, Stratégie et études, no 31. Paris, France. Retrieved October 2012, from http://ademe-et-vous.ademe.fr/strategieetudes-n-31-2-fevrier-2012

Ajzen, I. (1991). The theory of planned behavior. Organizational Behavior and Human Decision Processes, 50 , 179-211. http://dx.doi.org/10.1016/0749-5978(91)90020-T

Assemblée Nationale. (2012). Proposition de loi instaurant une tarification progressive de l'énergie no 150. Retrieved October 2012, from http://www.assemblee-nationale.fr/14/dossiers/tarification_progressive_energie.asp

Aune, M. (2007). Energy comes home. Energy Policy, 35, 5457-65. http://dx.doi.org/10.1016/j.enpol.2007.05.007

Boardman, B., \& Palmer, J. (2007). Electricity disclosure: The troubled birth of a new policy. Energy Policy, 35, 4947-58. http://dx.doi.org/10.1016/j.enpol.2007.04.021

Bourdieu, P. (1977). Outline of a Theory of Practice. UK: Cambridge University Press.

Brouard S., Gougou, F., Guinaudeau, I., \& Persico, S. (2012). Les Français, le nucléaire et la campagne présidentielle 2012. TriElec. Paris, France. Retrieved from http://www.cee.sciences-po.fr/en/elections-2012/541-les-francais-le-nucleaire-et-la-campagne-presidentielle .html

Chappells, H., \& Shove, E. (2005). Debating the future of comfort: environmental sustainability, energy consumption and the indoor environment. Building Research \& Information, 33(1), 32-40. http://dx.doi.org/10.1080/0961321042000322762

CICERO/Synovate. (2010). Den Store Norske Klima- og Miljøundersøkelsen 2010. Oslo, Norway.

Clancy, J., \& Roehr, U. (2003). Gender and Energy: Is there a Northern Perspective? Energy for Sustainable Development, 7(3), 44-9. http://dx.doi.org/10.1016/S0973-0826(08)60364-6

Commissariat Général au Développement Durable. (2010). Le budget 'énergie du logement': les déterminants des écarts entre les ménages. Le Point sur, no 56. Paris, France.

Commissariat Général au Développement Durable. (2011). Les perceptions sociales et pratiques environnementales des Français de 1995 à 2011. La revue du CGDD. Paris, France.

Commission de Régulation de l'Energie. (2011). L'ouverture des marchés de l'électricité et du gaz naturel pour les clients résidentiels. Baromètre annuel - vague 5. Energe-Info, LH2. Paris, France.

Commission de Régulation de l'Energie. (2012). Evolution du mix: les réseaux en première ligne. Paris, France. Décryptages no 28.

Devalière, I., Briant, P., \& Arnault, S. (2011). La précarité énergétique : avoir froid ou dépenser trop pour se chauffer. Insee Première no 1351. Paris, France.

Douglas, M. (1990). Risk as a forensic resource, Daedalus, 119(4). American Academy of Arts and Sciences.

Douglas, M., \& Wildavsky, A. (1983). Risk and Culture: An Essay on the Selection of Technological and Environmental Dangers. California: University of California Press.

EC. (2011). European Commission (2011/0172): Proposal for a Directive of the European Parliament and of the Council on Energy Efficiency. Retrieved May 2012, from $\mathrm{http} / /$ ec.europa.eu/energy/efficiency/eed/eed_en.htm

Eurostat. (2012). Communiqué de Presse, 78/2012, 25 May 2012. Retrieved October 2012, from http://epp.eurostat.ec.europa.eu/cache/ITY_PUBLIC/8-25052012-AP/FR/8-25052012-AP-FR.PDF

Fodor, F. (2012). Sustainable Development, Climate Change, Energy Saving: Discursive Developments of an Environmental Ethic. In S. Shmelev \& I. Smeleva (Eds.), Sustainability Analysis (pp. 179-202). An interdisciplinary Approach. New York: Palgrave Macmilan. 
Garabuau-Moussaoui, I. (2011). Energy-related logis of action throughout the ages in France: historical milestones, stages of life and intergenerational transmissions. Energy Efficiency, 4(4), 493-509. http://dx.doi.org/10.1007/s12053-011-9124-8

Hansla, A., Gamble, A., Juliusson, A., \& Gärling, T. (2008). Psychological determinants of attitude towards and willingness to pay for green electricity. Energy Policy, 36, 768-774. http://dx.doi.org/10.1016/j.enpol.2007.10.027

Henning, A. (2005). Equal Couples in Equal Houses: Cultural Perspectives on Swedish Solar and Bio-pellet Heating Design. In S. Guy \& S. A. Moore (Eds), Sustainable Architectures: Cultures and Natures in Europe and North America (pp. 89-104). New York: Spoon Press. http://dx.doi.org/10.4324/9780203412800_chapter_6

IEA. (2009). Energy statistics for France and Norway. Retrieved September 2012, from http://www.iea.org/stats/electricitydata.asp?COUNTRY_CODE=FR http://www.iea.org/stats/electricitydata.asp?COUNTRY_CODE=NO

Litvine, D., \& Wüstenhagen, R. (2011). Helping "light green" consumers walk the talk: Results of a behavioural intervention survey in the Swiss electricity market. Ecological Economics, 70, $462-74$. http://dx.doi.org/10.1016/j.ecolecon.2010.10.005

Maréchal, K. (2009). An evolutionary perspective on the economics of energy consumption: The crucial role of habits. Journal of Economic Issues, 43(1), 69-88. http://dx.doi.org/10.2753/JEI0021-3624430104

Markard, J., \& Holt, E. (2003). Disclosure of electricity products - lessons from consumer research as guidance for energy policy. Energy Policy, 31(14), 1459-74. http://dx.doi.org/10.1016/S0301-4215(02)00201-X

Ortner, S. (2006). Anthropology and Social Theory: Culture, Power, and the Acting Subject. Durham, USA: Duke University Press.

Peretti-Watel, P. (2010). La société du risque. Paris, France: La Découverte, collection repères.

Røpke, I. (2009). Theories of practice - new inspiration for ecological economic studies on consumption. Ecological Economics, 68, 2490-97. http://dx.doi.org/10.1016/j.ecolecon.2009.05.015

Sælen, H., Westskog, H., \& Strumse, E. (2012). Values, attitudes, and pro-environmental behaviours - is there a link? Results from a Norwegian survey. Economics Bulletin, 32(1), 486-93.

Sewell, W. H. (1992). A theory of structure: Duality, agency, and transformation. The American Journal of Sociology, 98(1), 1-29. http://dx.doi.org/10.1086/229967

Shove, E. (2004). Changing human behaviour and lifestyle: A challenge for sustainable consumption? In L. A. Reisch \& I. Røpke (Eds.), The ecological economics of consumption (pp. 111-31). Cheltenham, UK: Edward Elgar Publishing. http://dx.doi.org/10.1068/a42282

Shove, E. (2010). Beyond the ABC: climate change policy and theories of social change. Environment and Planning A, 42, 1273-85. http://dx.doi.org/10.1080/09613210802079322

Shove, E., Chappells, H., Lutzenhiser, L., \& Hackett, B. (2008). Comfort in a lower carbon society. Building Research \& Information, 36(4), 307-11.

SSB. (2012). Statistics Norway: "Inntektsstatistikk for hushald". Retrieved July 2012, from http://www.ssb.no/emner/05/01/ifhus/

Stern P. (2000). Toward a coherent theory of environmentally significant behaviour. Journal of Social Issues, 56, 407-24. http://dx.doi.org/10.1111/0022-4537.00175

Warde, A. (2005). Consumption and Theories of Practice. Journal of Consumer Culture, 5(2), $131-153$. http://dx.doi.org/10.1177/1469540505053090

Westskog H., Winther, T., \& Strumse, E. (2011). Addressing fields of rationality - a policy for reducing household energy consumption? In I. Galarraga et al. (Eds.), Handbook of Sustainable Energy, Chapter 22. Edward Elgar Publishing.

Westskog, H., \& Winther, T. (in progress). Electricity - commodity or common property? Implications of people's attitudes for the forming of sustainable energy policies.

Wilhite, H. (2008). New thinking on the agentive relationship between end-use technologies and energy-using practices. Energy Efficiency, 1, 121-130. http://dx.doi.org/10.1007/s12053-008-9006-x 
Wilhite, H., Nakagami, H., Masuda, T., Yamaga Y., \& Haneda H. (1996). A cross-cultural analysis of household energy use behaviour in Japan and Norway. Energy Policy, 24(9), 795-803. http://dx.doi.org/10.1016/0301-4215(96)00061-4

Wilhite, H., Shove, E., Lutzenhiser, L., \& Kempton, W. (2000). The legacy of twenty years of energy demand management: we know more about individual behavior but next to nothing about demand. In E. Jochem, J. Sathaye, \& D. Bouille (Eds.), Society, behaviour and climate change mitigation. London: Kluwer Academic Publishers.

Winther, T. (2008). The Impact of Electricity. Development, Desires and Dilemmas. Oxford: Berghahn Books.

Winter, T., \& Ericson, T. (2012). Matching policy and people? Household responses to the promotion of renewable electricity. Energy Efficiency (published online 2012).

Zerubavel, E. (2006). The elephant in the room: Silence and denial in everyday life. New York: Oxford University Press. http://dx.doi.org/10.1093/acprof:oso/9780195187175.001.0001

\section{Notes}

Note 1. For example, the EU has set a goal of reducing energy consumption by 20 percent (compared with projected levels) and achieving a 20 percent share in renewable energy sources by 2020 . A desire for energy security also informs this goal.

Note 2. The European Directive 2003/54/EC puts the obligation on national energy authorities to ensure that electricity suppliers provide their customers with information about their fuel mixes on the electricity bill. Within this labelling scheme, suppliers must display the shares of renewables, fossil and nuclear fuels involved in the generation of electricity, as well as the corresponding amounts of $\mathrm{CO}_{2}$ emissions and nuclear waste. The labelling scheme is based on an underlying market for issuing and trading Guarantees of Origin.

Note 3. EU's proposed Energy Efficiency Directive states that information campaigns are obligatory (EC, 2011).

Note 4. The study forms part of a research project led by the Center for International Climate Research (CICERO) in Oslo, called "Do customer information programs influence energy consumption?" funded by the Research Council of Norway from 2009 to 2011 (project no. 190769/S60).

Note 5. These interviews complete research studies we carried out on the environment and energy management. The French part of this study was conducted under the framework of the European Energy Efficiency Research Centre (ECLEER), in partnership with Celsa-Paris-Sorbonne - our thanks to Claire Burlat.

Note 6. Based on a list of customers obtained through the local supplier, the Norwegian interviewees were recruited by the researcher by telephone. At first, people were very hesitant to agree to an interview, but this changed slightly after the researcher had been interviewed on the local radio NRK Finnmark and could refer to this interview when approaching people on the phone. It seemed that most of those who agreed to an interview had a particular interest in energy, electricity and new energy technology, so they are not fully representative of the population.

Note 7. The remaining production in France includes 11 percent thermal power and 15 percent renewable sources, of which 12 percent is hydro (Commission de Régulation de l'Energie, 2012).

Note 8. Norway exchanges power with Sweden, Russia, Finland, Denmark, the Netherlands and Germany.

Note 9. The European Directive 2003/54/EC required EU member states to open up their national energy markets for competition.

Note 10. The French term "précarité énergétique" implies that a household spends more than 10 percent of their budget on energy, cf. the notion of "energy poverty" (Clancy \& Roehr, 2003).

Note 11. As of April 2012, 89 suppliers offering electricity to Norwegian households were listed on the home page of the Norwegian Competition Authority (www.konkurransetilsynet.no).

Note 12. The total price of electricity (energy, transport and taxes) to households in France and Norway is about 11 cents per $\mathrm{kWh}$, that is, 66 percent of the average in the EU/EFTA region (for France: Eurostat, 2012; for Norway: SSB, 2010).

Note 13. The average, annual consumption of electricity per capita in the residential sector is $2701 \mathrm{kWh}$ in France and 7272 in Norway (IEA, 2009). We assume that the population of France is 63 million and that of Norway is 5 million. 
Note 14. In this estimation we use 55000 EUR as the median income per household after tax (SSB, 2010), $22000 \mathrm{kWh}$ as the average level of annual consumption within our research area and 9 cents as the electricity cost in our research area in 2009.

Note 15. As Fodor (2012) notes, in 2007 the French media perceived climate change as a fact requiring immediate action. Two years later "climate sceptics" called it into question and experts debated the issue. In 2011, just after Fukoshima, media reports were more consensual: climate change was a recognised fact, and Fukushima had demonstrated the need for innovation. However, only a few months after the nuclear accident, the European financial crisis was a reality and became the dominant, pressing concern in French public debate at the expense of environmental risks.

Note 16. On its bills, EDF states the fuel mix of the electricity it sells to customers. Our French respondents had limited knowledge about other suppliers and their offers of 100 percent renewable electricity. There are websites in France (e.g. at Commission de Régulation de l'Energie) where customers can compare companies and make a choice of supplier depending on price, the electricity's origin, etc. None of our respondents referred to such websites/lists.

Note 17. 42 percent of French households confirm that they know they can choose electricity supplier, and 57 percent consider themselves to be well informed about this option (Commission de Régulation de l'Energie, 2011). Among those who have changed supplier, as many as 33 percent believe that they continue to receive electricity from EDF (ibid.).

Note 18. In French, the word for income or municipality tax is impot, whereas value added taxes (VAT) are referred to as $\operatorname{tax}$ (TVA). In the accounts we refer to, the word impot was not used.

Note 19. In a pre-study recently conducted for another Norwegian project we focused on people's preferences for shifting electricity prices according to the hour of the day (not offered today). Interestingly, in four out of nine conversations, the risk of fire was brought up as an issue. This may indicate that some Norwegians already tacitly take precautions by not using appliances at night or when away from their homes, but avoid bringing the issue up in conversations about the present system. This issue needs further investigation.

Note 20. See Garabuau-Moussaoui (2011) for a treatment of the significance of generational belonging for people's energy savings habits in France.

Note 21. In France, people stressed more often and in more detail the advantage of choosing A up to A+++ labelled appliances (which are technically more energy efficient compared to appliances marked B-E). When Norwegians were asked about the label of their various appliances, they often did not know.

Note 22. In this region there is midnight sun from May until late July when the average temperature is 12 degrees Celsius (www.eKlima.no). From November to late January the sun is always below the horizon and the mid temperature in January is minus 12 degrees Celsius.

Note 23. Perceptions of comfort are culturally determined (Wilhite et al., 1996, Chappells \& Shove, 2005). Our material confirms that people often use physiological arguments, for example relating to body and health, when accounting for the notion of comfort (Chappells \& Shove, 2005).

Note 24. Shove (2010) refers to Ajzen's (1991) notion "ABC" (attitudes - behaviour - choice) and insists that Stern (2000), although denoting C as "contextual factors", has maintained conceptual focus on individual choice. 